\title{
Retroclival subdural hematoma associated with warfarin: A case report
}

\author{
Sinan BAHADIR \\ Department of Neurosurgery, Amasya University Faculty of Medicine, Amasya, Turkey
}

\begin{abstract}
Retroclival subdural hemorrhage is a rare entity. Apart from trauma, it may occur due to rupture of an aneurysm, pituitary apoplexy and spontaneously. Very few cases are associated with bleeding disorders.A 62-year-old female patient who was under warfarin treatment was found to have subdural hemorrhage in the retroclival area. Headache complaint was rapidly relieved by steroid treatment. She fully recovered in a month. Spontaneous retroclival hemorrhage is rarely associated with anticoagulant agents. Though it's hardly a lethal condition, steroids can provide quick pain relief.
\end{abstract}

Keywords: clivus; retroclival; subdural; hematoma; hemorrhage; warfarin

\section{INTRODUCTION}

Hemorrhage into retroclival subdural space is uncommon and most commonly occur due to trauma, pituitary apoplexy and vascular pathologies. In rare cases, bleeding disorders, either secondary to disease or iatrogenic, accompany this entity. ${ }^{1}$

In this report, we present a rare case of retroclival subdural hematoma $(\mathrm{RCSDH})$ in a patient who was on warfarin therapy.

\section{CASE REPORT}

A62-year-old female patient admitted to neurology outpatient clinic with complaints of dizziness and vertigo for 2 days. She was receiving warfarin for atrial fibrillation. Her neurological examination was normal.A computed tomography (CT) scan revealed a hyperdense lesion in the subdural space at the craniocervical junction (Figure 1a). This was followed by a cervical magnetic resonance imaging (MRI) which revealed subacute subdural hemorrhage extending from basal cisterns rostrally to cervicothoracic junction caudally (Figure 1b). It was widest between $\mathrm{C} 1$ and $\mathrm{C} 3$ levels. Her laboratory tests revealed an international normalized ratio (INR) of 4.80 . Cessation and reversal of anticoagulation with fresh frozen plasma and vitamin $\mathrm{K}$ was followed by neurosurgery consultation.

Our initial neurological examination revealed no abnormal findings. We took over the patient to Neurosurgery Department for observation. We continued hypertension treatment and started analgesics. Despite no neurological impairment, headache complaint increased and reached a plateau at 5th day of admission. There was no significant change in follow-up MRI at 8th day. For persistent headache, we placed her on oral prednisolone $60 \mathrm{mg} /$ day at 9th day, a modified treatment for spontaneous cervical subdural hematoma. ${ }^{2}$ The patient described significant decrease of headache the following day. She remained stable and was discharged under prednisolone with a tapering plan at 11th day of admission.

After 1 month, she had no symptoms and cranial and cervical MRI showed total reabsorption of hematoma (Figure 2).

\section{DISCUSSION}

Retroclival hematomas may be either epidural or subdural where the latter is rarer. In the retroclival area, epidural and subdural spaces are seperated by tectorial membrane which is firmly attached to body of the axis posteriorly. ${ }^{3}$ Unlike epidural hematoma, subdural hematoma is not bounded by tectorial membrane and its ability to disperse through subdural space through spinal canal usually prevents it accumulating in one region and exerting mass effect on brainstem. ${ }^{3}$

RCSDH, similar to its epidural counterpart, most commonly occurs due to blunt head trauma, followed by pituitary apoplexy or aneursym

Address correspondence to: Dr. Sinan BAHADIR, Amasya Üniversitesi Tıp Fakültesi, Sabuncuoğlu Şerefeddin Eğitim ve Araştırma Hastanesi, Beyin ve Sinir Cerrahisi Anabilim Dalı, Amasya, Turkey. Tel: +90 53264665 72, E-mail: sinanbahadir@windowslive.com

Date of Submission: 11 February 2021; Date of Acceptance: 28 June 2021

https://doi.org/10.54029/2021nuu 


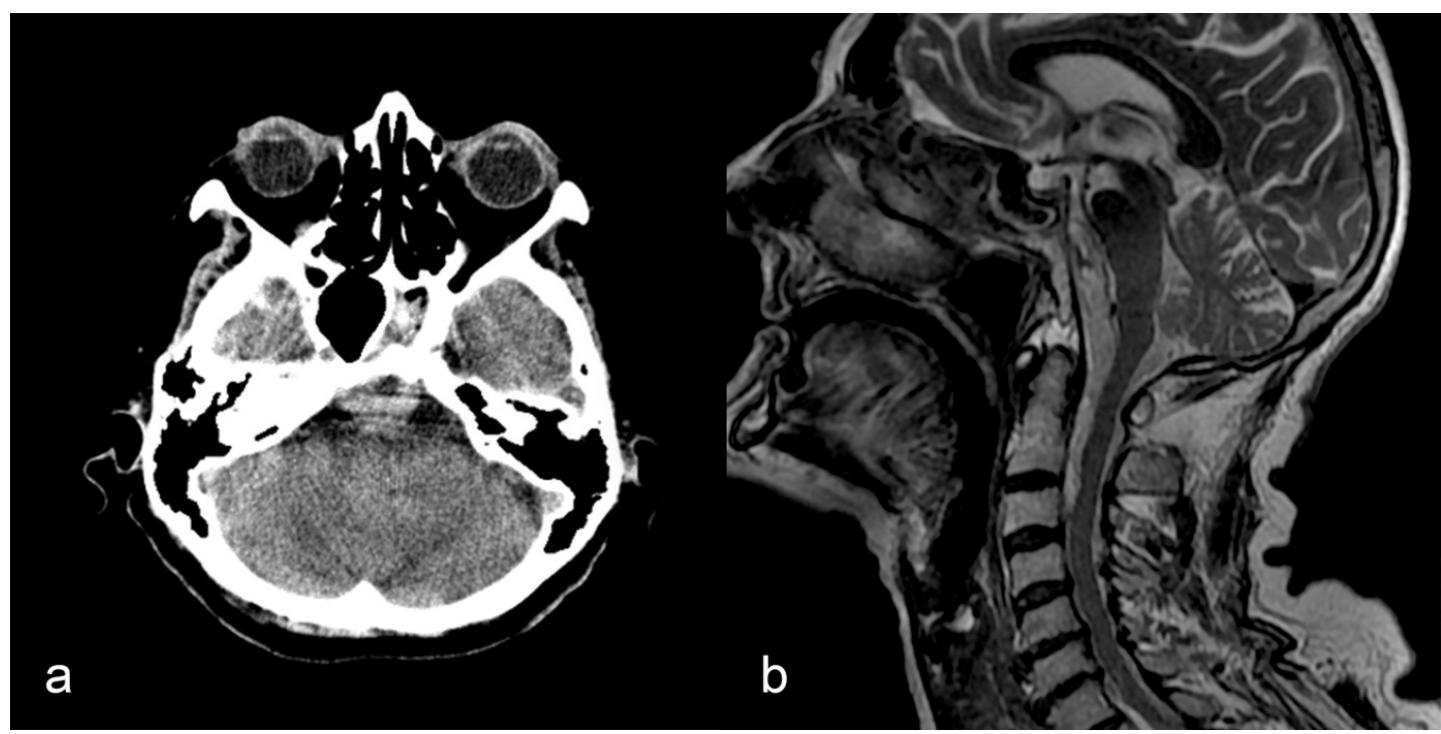

Figure 1: Radiological images at the time of admission. a Hemorrhage posterior to clivus as hyperdensity in axial CT scan. b Sagittal T2 weighted MRI demonstrates the extent of hemorrhage in subdural space, note that it extends below tectorial membrane's attachment at C2 level.

rupture, and rarely spontaneously. ${ }^{4}$ Patients with bleeding disorders -either genetic, acquired or iatrogenic- may have increased risk for hemorrhage into this area. ${ }^{1,5,6} \mathrm{RCSDH}$ usually present with acute onset severe headache and/or cranial nerve palsies, especially abducens nerve. Other symptoms may include nausea, vomitting and progressive deterioriation. ${ }^{4}$

RCSDH can be visualized by CT or MRI with characteristic appearance of hemorrhage. CT is usually the first choice of imaging both due to

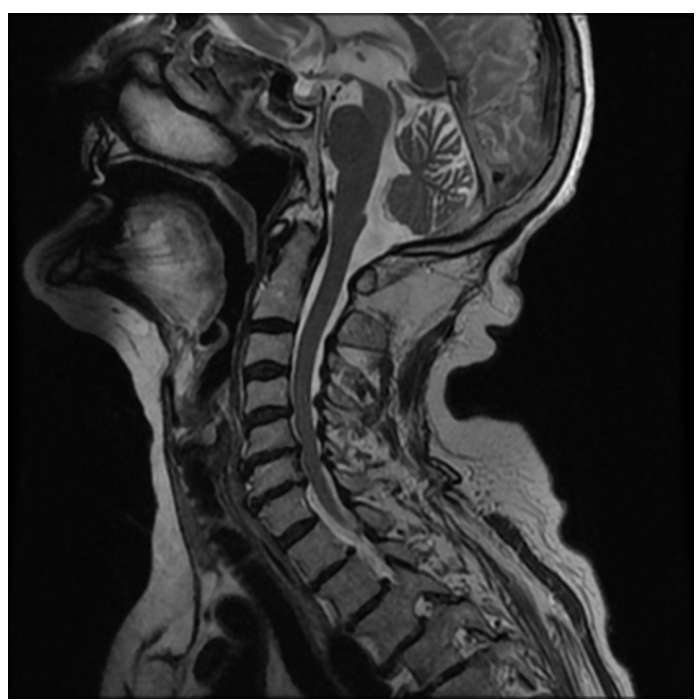

Figure 2: Sagittal T2 weighted MRI taken at 1st month reveals total reabsorbtion of hematoma. trauma and clinical symptoms that can mimic an aneurysmal subarachnoid hemorrhage. ${ }^{3}$ However, since retroclival area is prone to bone artifact, MRI provides more detail regarding its compartmental location and extension as well as integrity of ligaments in the setting of trauma. ${ }^{3}$ Especially sagittal sections are helpful in differentiting it from epidural hemorrhages since placement of hematoma regarding tectorial membrane can easily be identified. ${ }^{3}$

There are very few cases reporting RCSDH associated with bleeding disorders. Two hemophilia patients had RCSDH following trauma. Though both were managed conservatively, one died. ${ }^{5,7}$ One patient with thrombocytopenia had spontaneous bleeding without trauma and died in a short time. ${ }^{6}$

In literature, only 3 cases were reported to have RCSDH while on anticoagulant therapy. In one case, we only managed to access the abstract, so type of anticoagulant drug and INR level is unknown to us. ${ }^{8}$ Of the remaining, one was on enoxaparine and warfarin treatment at the same time and had normal laboratory parameters. ${ }^{1}$ The last patient was on warfarin treatment with INR level above therapeutic range. ${ }^{9}$ Similarly, our case was also on warfarin treatment and her INR was also above therapeutic range. Although the data is limited to draw a definite conclusion, it seems that warfarin may cause RCSDH if INR exceeds therapeutic range, but when combined with another anticoagulant agent bleeding may occur despite normal coagulation parameters. 
Usually RCSDH cases were diagnosed with CT initially. However in some cases, especially the victims of abusive trauma CT failed to detect RCSDH. ${ }^{10-12}$ Though conventional angiography is performed to evaluate vascular aneurysms in most nontraumatic cases, among 3 cases of aneurysm rupture, both CT and MR angiography were able to detect aneurysm. ${ }^{13-15}$ Regarding diagnostic modalities, it can be said that though CT is almost always the initial imaging study, it may not be sufficient to detect RCSDH in all cases, especially abusive traumatic cases. These patients may require MRI. Additionally, conventional angiography may not be necessary to rule out vascular aneurysms since CT or MRI angiography were capable of detecting all aneurysms in these cases.

RCSDH is usually managed conservatively. However, type of conservative management was rarely described since most reports focused on neurological outcome. But it must be noted that despite good outcomes, these patients suffer from severe headache which cause discomfort and anxiety. What we observed in our case was that the headache remained unchanged for a week and rapidly declined after we initiated steroid treatment. It is unknown whether this was a coincidence or an effect of steroid since previous reports do not give any data to support or contradict this observation.

$\mathrm{RCSDH}$ is a rare entity where different etiologies predominates in adults and children. $\mathrm{CT}$ and MRI are choice of imaging and CT and MR angiography may be capable of identifying vascular pathologies. It can lead to death if there is an existing underlying bleeding disorder. Most patients recover completely. Apart from primary pathologies or a few instances where it causes mass effect, they do not require surgical intervention. Steroid treatment may result in rapid relieve of headache.

\section{DISCLOSURE}

Financial support: None

Conflict of interest: None.

\section{REFERENCES}

1. Sever A, Rheinboldt M, Doshi P. Spontaneous retroclival subdural hematoma associated with anticoagulation. Appl Radiol 2017;46:38-41.

2. Song TJ, Lee JB, Choi YC, Lee KY, Kim WJ. Treatment of spontaneous cervical spinal subdural hematoma with methylprednisolone pulse therapy. Yonsei Med J 2011;52:692-4.
3. Koshy J, Scheurkogel MM, Clough L, Huisman TA, Poretti A, Bosemani T. Neuroimaging findings of retroclival hemorrhage in children: a diagnostic conundrum. Childs Nerv Syst 2014;30:835-9.

4. Nguyen HS, Shabani S, Lew S. Isolated traumatic retroclival hematoma: case report and review of literature. Childs Nerv Syst 2016;32:1749-55.

5. Sahlu A, Getachew K, Mekonnen A. Traumatic retroclival subdural hematoma in a child with hemophilia. World Neurosurg 2020;133:112-20.

6. Krishnan P, Kartikueyan R, Chowdhury SR, Das S. Retroclival subdural hematoma: an uncommon site of a common pathology. Neurol India 2013;61:550-2.

7. Myers DJ, Moossy JJ, Ragni MV. Fatal clival subdural hematoma in a hemophiliac. Ann Emerg Med 1995;25:249-52.

8. Guilloton L, Godon P, Drouet A, Guerard S, Aczel $\mathrm{F}$, Ribot C. [Retroclival hematoma in a patient taking oral anticoagulants]. Rev Neurol (Paris) 2000;156:392-4.

9. Amalnath SD. Teaching NeuroImages: Godtfredsen syndrome due to retroclival subdural hematoma. Neurology 2018;91:e999-e1000.

10. Azizyan A, Miller JM, Azzam RI, et al. Spontaneous retroclival hematoma in pituitary apoplexy: case series. J Neurosurg 2015;123:808-12.

11. Silvera VM, Danehy AR, Newton AW, et al. Retroclival collections associated with abusive head trauma in children. Pediatr Radiol 2014;44 (Suppl 4):S621-31 .

12. Narvid J, Amans MR, Cooke DL, et al. Spontaneous retroclival hematoma: a case series. J Neurosurg 2016;124:716-9.

13. Kim MS, Jung JR, Yoon SW, Lee CH. Subdural hematoma of the posterior fossa due to posterior communicating artery aneurysm rupture. Surg Neurol Int 2012;3:39.

14. Bartoli A, Kotowski M, Pereira VM, Schaller $\mathrm{K}$. Acute spinal epidural hematoma and cranial interdural hematoma due to a rupture of a posterior communicating artery aneurysm: case report. Neurosurgery 2011;69:E1000-4; discussion E1004.

15. Brock S, Prada F, Maccagnano E, Giombini S. Interdural haemorrhage of the posterior fossa due to infraclinoidal carotid artery aneurysm rupture. Acta Neurochir (Wien) 2010;152:1543-6. 